\title{
A Lightweight Tile Structure Integrating Photovoltaic Conversion and RF Power Transfer for Space Solar Power Applications
}

\author{
Eleftherios E. Gdoutos, ${ }^{*}$ Christophe Leclerc ${ }^{\dagger}$ Fabien Royer, ${ }^{\dagger}$ \\ Michael D. Kelzenberg, ${ }^{\ddagger}$ Emily C. Warmann, ${ }^{\dagger}$ Pilar Espinet-Gonzalez, ${ }^{\dagger}$ Nina Vaidya, ${ }^{\dagger}$ \\ Florian Bohn, ${ }^{\S}$ Behrooz Abiri, ${ }^{\ddagger}$ Mohammed R. Hashemi, ${ }^{\ddagger}$ Matan Gal-Katziri, ${ }^{\ddagger}$ Austin Fikes, ${ }^{\ddagger}$ \\ Harry A. Atwater, ${ }^{\top}$ Ali Hajimiri, ${ }^{\prime}$ and Sergio Pellegrino** \\ California Institute of Technology, Pasadena, CA, 91125, USA
}

\begin{abstract}
We demonstrate the development of a prototype lightweight $\left(1.5 \mathrm{~kg} / \mathrm{m}^{2}\right)$ tile structure capable of photovoltaic solar power capture, conversion to radio frequency power, and transmission through antennas. This modular tile can be repeated over an arbitrary area to form a large aperture which could be placed in orbit to collect sunlight and transmit electricity to any location. Prototype design is described and validated through finite element analysis, and high-precision ultra-light component manufacture and robust assembly are described.
\end{abstract}

\section{Introduction}

Collecting solar power in space and transmitting the energy wirelessly to Earth through microwaves enables terrestrial power availability unaffected by weather or time of day. Solar power could be continuously available anywhere on earth.

The fundamental technologies necessary for realizing space-based solar power (SSP) have been established. Solar cells are used widely in space; in fact, the first commercially successful use of Si photovoltaic (PV) cells was to power early space satellites. ${ }^{1}$ The rectenna, a ground-based receiver technology for the microwavefrequency SSP concept, was developed by Brown more than 50 years ago. ${ }^{2}$ Space-based solar power was first formally proposed in $1968 .^{3}$ Major studies of the concept were funded by DOE and NASA in the 1970s and 80s, concluding that while significant R\&D would be required to commercialize space solar, the associated challenges were not beyond what was expected for alternative systems of similar capability. To date, although many implementations have been conceptualized, ${ }^{5-8}$ none have been realized due to the mass and number of launch of vehicles required to place the necessary infrastructure in orbit. Thus, from a structural standpoint, a key performance metric of SSP is the areal mass $\left(\mathrm{kg} / \mathrm{m}^{2}\right)$ of the space infrastructure.

In 2007, a panel-based system tethered to a central bus, transmitting $60 \mathrm{~W} / \mathrm{kg}$ at $5.8 \mathrm{GHz}$, with areal mass density of $5.2 \mathrm{~kg} / \mathrm{m}^{2}$, was proposed by Sasaki et al. ${ }^{9}$ Another approach, transmitting $110 \mathrm{~W} / \mathrm{kg}$ using $\lambda \sim 0.8 \mu \mathrm{m}$ lasers, with areal mass density of $2.3 \mathrm{~kg} / \mathrm{m}^{2}$, was proposed in $2009 .{ }^{10}$ In 2012, Mankins conceptualized a number of modular systems incorporating phased-array beaming with a specific power of

\footnotetext{
*Research Scientist, Graduate Aerospace Laboratories, MC 105-50. AIAA Member. E-mail: egdoutos@caltech.edu.

${ }^{\dagger}$ Graduate Student, Graduate Aerospace Laboratories, MC 105-50. AIAA Student Member.

$¥$ Applied Physics and Materials Science MC 128-95.

$\S$ Electrical Engineering, MC 136-93.

『Howard Hughes Professor of Applied Physics and Materials Science; Director, Joint Center for Artificial Photosynthesis, Applied Physics and Materials Science, MC 128-95.

" Bren Professor of Electrical Engineering and Medical Engineering; Executive Officer for Electrical Engineering; Co-Director, Space-Based Solar Power Project, Electrical Engineering, MC 136-93.

** Joyce and Kent Kresa Professor of Aeronautics and Civil Engineering; Jet Propulsion Laboratory Senior Research Scientist; Co-Director, Space-Based Solar Power Project, Graduate Aerospace Laboratories, MC 105-50. AIAA Fellow. E-mail: sergiop@caltech.edu
} 
$57.5 \mathrm{~W} / \mathrm{kg}$ and an areal mass density of $2.25-4.5 \mathrm{~kg} / \mathrm{m}^{2}{ }^{11}$ More recently, in 2013, Jaffe and McSpadden developed and lab-tested a prototype of a modular "sandwich" panel which collects solar power and transmits $9 \mathrm{~W} / \mathrm{kg}$ at $2.45 \mathrm{GHz}$, weighing $19.2 \mathrm{~kg} / \mathrm{m}^{2} .{ }^{12}$

In 2016, an architecture for an ultralight system that enables an SSP mission assuming today's launch costs was described. ${ }^{13}$ The architecture is based on the modular assembly of multifunctional lightweight tiles, each with the capability of independently collecting sunlight, converting it to RF, and transmitting the RF power to Earth. A mockup tile was developed and demonstrated, and a prototype of the solar cell subassembly was presented earlier this year. ${ }^{14}$

Here, we present the design, component manufacture, and assembly of the first functional lightweight tile prototype, with areal mass density of $1.5 \mathrm{~kg} / \mathrm{m}^{2}$. Section II describes the concept of the tile, the specific prototype design, and design verification with finite element analysis. Section III presents the prototype's component manufacture and assembly. Section IV discusses the performance characteristics of the prototype and future design iterations.

\section{Tile concept and prototype design}

The tile must collect sunlight, convert it to RF electrical power, then wirelessly transmit that power with proper phase to enable optimal reception of the energy by a distant receiver. The incident energy is first converted to DC electricity by PV solar cells, then to RF using integrated circuits. As shown in Figure 1a, a tile contains optical reflectors that concentrate incoming sunlight onto PV cells, and an integrated circuit (IC) that converts the incoming DC power to microwaves for transmission through an antenna array. In a space solar mission, a multitude of these tiles would be repeated and structurally integrated into strips and spacecraft modules such that all tiles function in unison to form a directive RF beam (Figure 1b). ${ }^{13}$

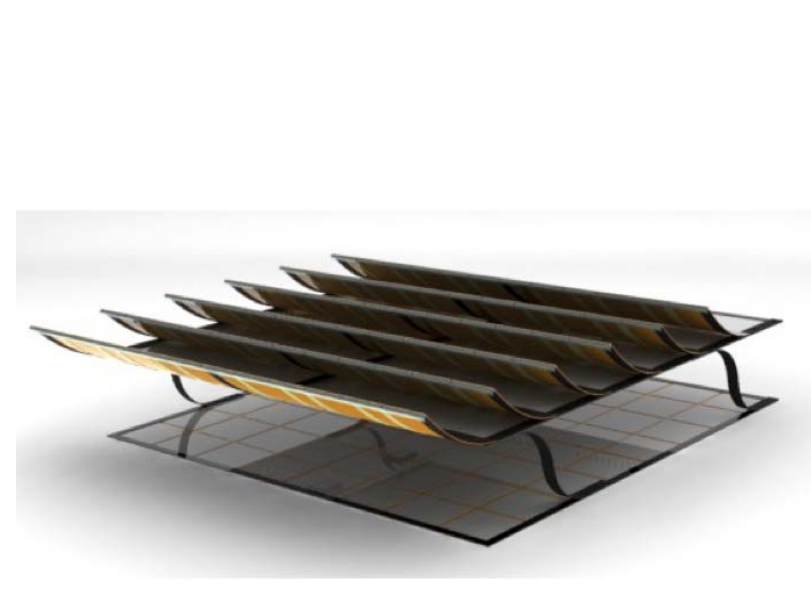

(a) Tile concept.

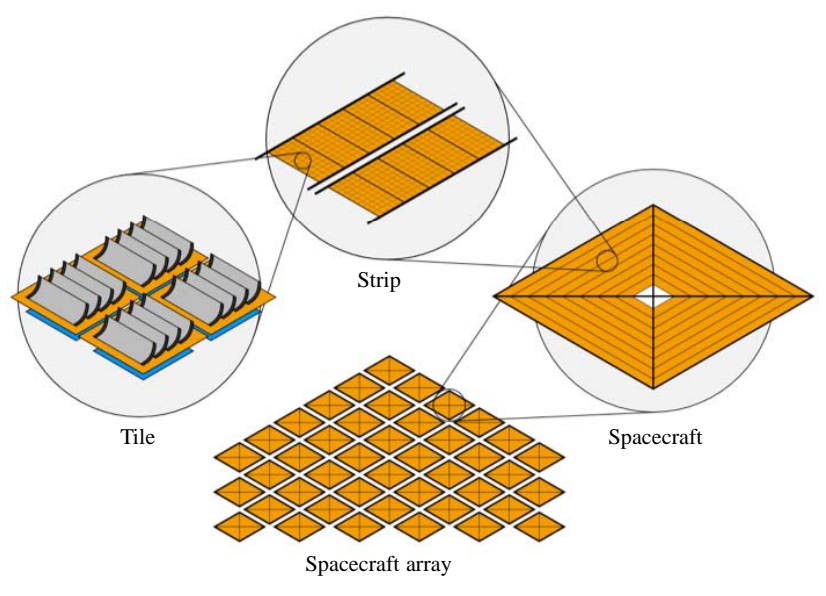

(b) Tiles arranged into strips which are integrated into spacecraft which can fly as arrays; the tile is the functional element.

Figure 1. (a) Tile concept that collects solar energy and transmits it at microwave frequency; (b) schematic demonstrating tiles integrated into strips, which form spacecraft modules, which can fly as array of spacecraft; in all cases all tiles function in unison to produce a single beam.

Tile modularity is advantageous in terms of mass, system complexity, robustness, and scalability. Integration of solar power and RF conversion in one tile voids the need for a power distribution network throughout the structure, reducing weight and complexity. In a system with a multitude of tiles one tiles failure does not impact other parts of the system. Missions based on an integrated modular tile are flexible in that the specific dimensions are not dependent on the basic tile design, and therefore can be adapted for various applications. Finally, tile modularity ensures that an existing mission can be expanded with the addition of tiles over time.

\section{II.A. Tile design}

The first tile prototype was designed to demonstrate the capability of powering the RF to DC integrated circuit (IC) and forming a microwave beam, resulting in a power requirement of approximately $2 \mathrm{~W}$. Accounting 
for expected power losses due to imperfect light concentration arising from various shape inaccuracies and power losses during transmission to the IC, the tile was designed to contain three $165 \mathrm{~mm} \times 100 \mathrm{~mm}$ planes with a total height of $12 \mathrm{~mm}$. Each plane performs a different function: the PV plane contains concentrators that focus the light onto solar cells; the power transfer plane contains the IC that converts incoming DC power from the solar cells to microwaves; the antenna plane transmits the power as a focused RF beam. The three planes were independently developed for modularity. Table 1 lists and describes all the components included in the tile prototype. A CAD model of the prototype design is shown in Figure 2. Design and fabrication of solar concentrators are discussed in detail in Sections II.B and III.A, respectively.

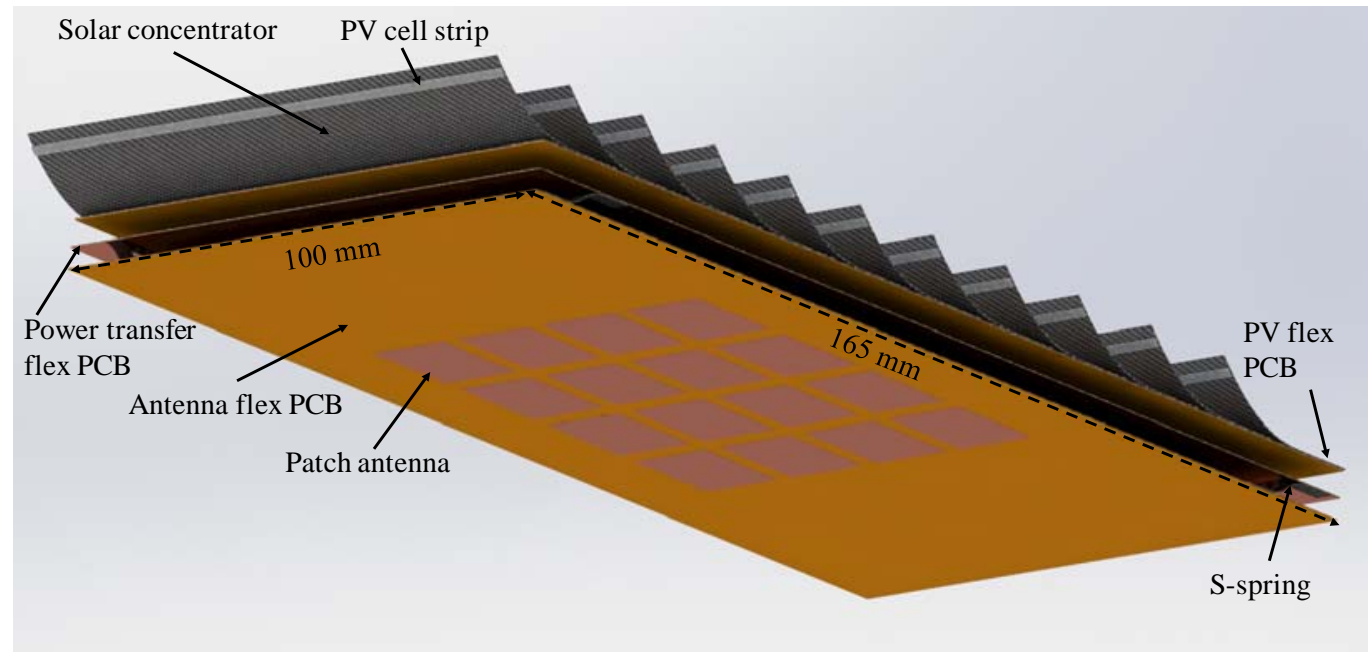

Figure 2. Tile prototype CAD model.

Table 1. First tile prototype component list and description.

\begin{tabular}{lll} 
Component & Description & Quantity \\
\hline Solar concentrators & $\begin{array}{l}\text { Parabolic, 8-ply CFRP coated with smoothing polymer and Ag } \\
\text { reflective layer }\end{array}$ & 11 \\
Solar cell strips & $\begin{array}{l}\text { 1.0 mm wide, triple junction on Ge with glass cover, mounted } \\
\text { on polyimide strips }\end{array}$ & 11 \\
IC & Converts DC power to RF & 1 \\
PV flex PCB & Routes power from solar cells to IC & 1 \\
Power transfer flex PCB & $\begin{array}{l}\text { Routing layers for RFIC and antennas and ground plane for } \\
\text { antennas }\end{array}$ & 1 \\
Antenna flex PCB & Flexible patch antennas & 1 \\
S-springs & Collapsible CFRP structure providing 3 mm spacing between & 4 \\
& antenna plane and power transfer plane & \\
Plane spacers & Create separation between PV plane and power transfer plane & 4 \\
Frames & $400 \mu m$ thick CFRP supporting flex PCB's & 3
\end{tabular}

\section{II.B. Solar concentrator design}

Solar concentrators enable mass reduction for currently available solar cells which require protection from radiation by reducing the amount of protective material needed. In this tile, solar concentrators arranged along its length, focus incident light on $1 \mathrm{~mm}$ wide by $100 \mathrm{~mm}$ long photovoltaic strips attached to the backside of the subsequent concentrator, as shown in Figure 3. The concentration ratio is $15 \mathrm{x}$ and the target shape is given by the function $y=0.033 x^{2}$. A tile includes 11 concentrators at a nominal $15 \mathrm{~mm}$ spacing (pitch), 10 of which have PV cell strips that accept incoming light from the preceding concentrator. For 
robustness during assembly, the PV cell strips were nominally positioned $2 \mathrm{~mm}$ from the top edge of the concentrator (backset).

Concentrator material choice is a trade-off between manufacturability, weight, and shape accuracy. The thinner the concentrator, the lighter it will be, however, larger deviations from its desired shape would be expected. We investigated a range of materials for manufacturing concentrators, including polymer or metallic thin films supported by structural frames and monolithic structures made of various CFRP laminates.

For the first integrated tile described here, we manufactured concentrators out of an 8-ply $[0 / 90 /+45 /-$ 45] $]_{s}$ CFRP laminate, $180 \mu m$ thick, using T800-17gsm carbon fiber and ThinPreg120EPHTg-402 resin. This material choice represented a balance between manufacturability and mass, while enabling an opportunity for further mass reduction in the future by using a laminate with fewer plies.

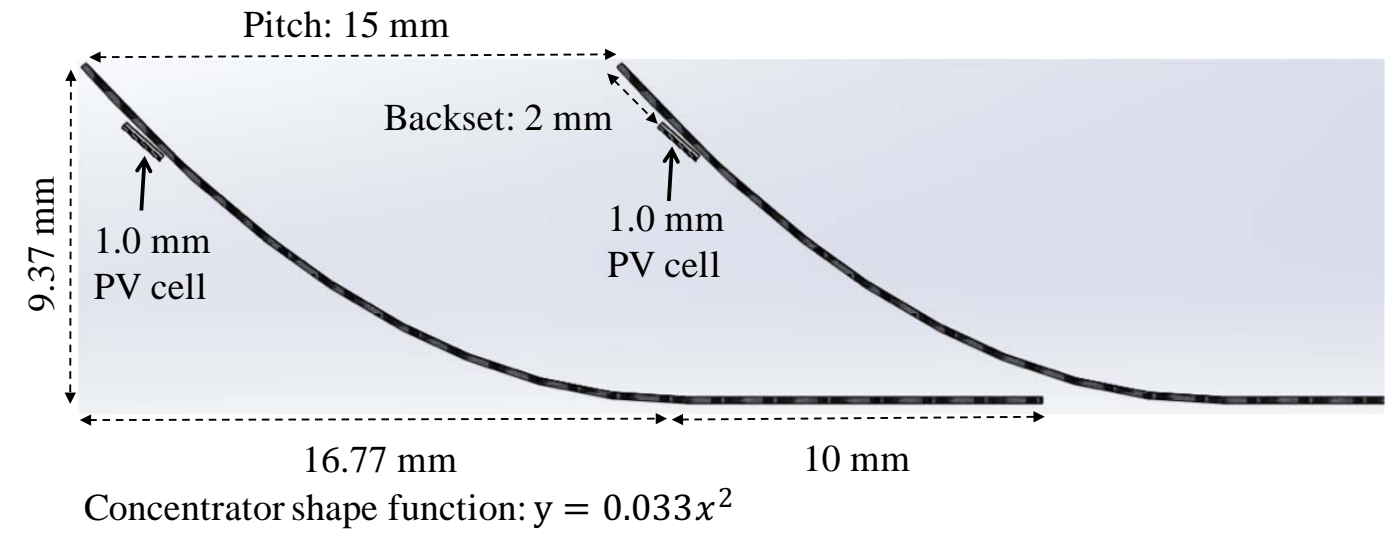

Figure 3. Side view of two modeled concentrators indicating design shape and dimensions.

\section{II.C. Design verification with finite element analysis}

In order to validate the prototype design under laboratory operating conditions, we performed a sequentially coupled thermal-mechanical finite element analysis. The objectives of the study were to verify that (i) the maximum temperature expected at the solar cells is within the operational profile; and (ii) the deformation of the prototype under self-weight and thermal loading would not distort the concentrators sufficiently to degrade performance.

The finite element analysis (FEA) model was developed by directly importing the CAD geometry into the Abaqus software. The geometry was meshed with 210,968 brick elements: heat transfer (DC3D8) elements were used for the thermal analysis and continuum shell elements (SC8R) were used for the mechanical analysis. Continuum shell elements are advantageous in that they can be used to approximate shell behavior in a 3D geometry. Tie constraints were used to simulate bonded surfaces. Seven materials were defined to capture the overall geometry. A global temperature distribution was obtained from the thermal analysis and was used as input to the mechanical analysis, which included gravitational loading. The thermal analysis loading corresponded to the heat flux equivalent to the intensity of one sun concentrated on the solar cells, assuming no losses or scattering in the concentrators.

Tables 2 and 3 list the loads/boundary conditions, and material properties used in the FEA.

The temperature distribution obtained as a result of the thermal analysis is shown in Figure 4a. The maximum predicted temperature of $345 \mathrm{~K}$ is within the operational temperature of the solar cells. The combined deformation of the concentrators resulting from the thermal distribution shown in Figure 4a and self-weight is shown in Figure 4b. The deformation profile varies depending on the location of the concentrator and its maximum value is approximately $300 \mu \mathrm{m}$ in magnitude. This degree of deformation was assumed negligible for this prototype. 
Table 2. Loads and boundary conditions used in sequentially coupled thermal-mechanical analysis.

\begin{tabular}{|c|c|c|}
\hline Load/BC & Location & Value \\
\hline PV cell heat flux & All PV cell strips & $78 \mathrm{~mW} / \mathrm{mm}^{3}$ \\
\hline Convection & All surfaces & $\begin{array}{l}\text { Convection coefficient } 5 \times 10^{-3} \mathrm{~mW} / \mathrm{mm}^{2} \mathrm{~K} \text { and } \\
\text { ambient temperature } 300 \mathrm{~K}\end{array}$ \\
\hline Radiation & All surfaces & $\begin{array}{l}\text { Emissivity coefficient } 0.8 \text { and ambient tempera- } \\
\text { ture } 300 \mathrm{~K}\end{array}$ \\
\hline Gravity & Whole model & $9810 \mathrm{~mm} / \mathrm{s}^{2}$ \\
\hline Hold in place & Power transfer plane outer edge & All displacements zero \\
\hline
\end{tabular}
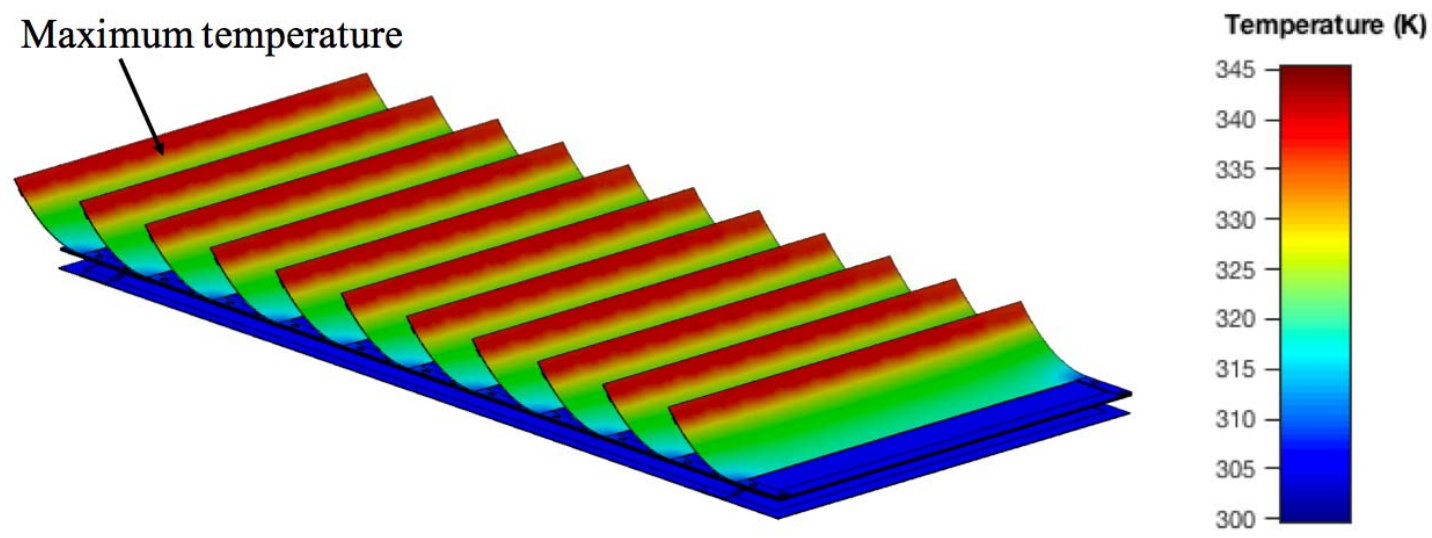

(a) Thermal FEA temperature distribution

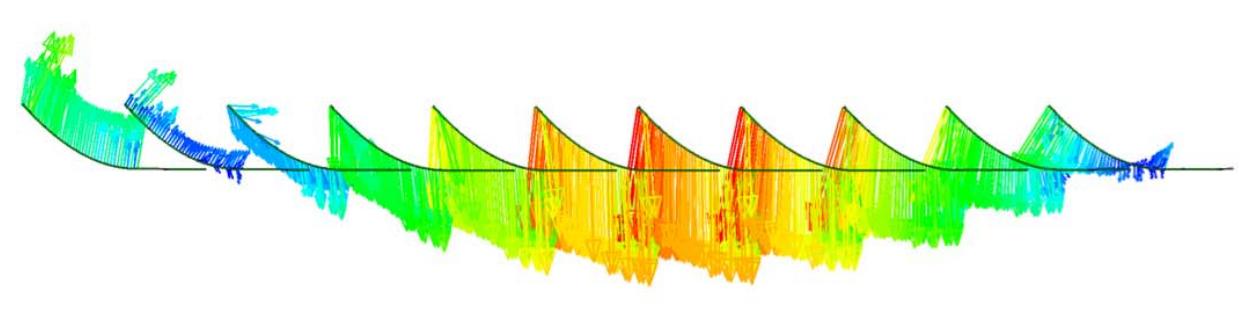

Displacement magnitude $(\mu \mathrm{m})$

(b) Mechanical FEA displacement profile

Figure 4. (a) Temperature distribution of tile prototype as a result of thermal flux corresponding to one sun modeled with FEA; (b) side view of concentrators with arrows indicating the displacement vector field resulting from thermal loading and self-weight.

\section{Tile assembly and concentrator manufacture}

\section{III.A. Solar concentrator manufacture}

Solar concentrators were composed of four layers, with the main structural component being $80 \mu m$-thick 8-ply CFRP. A smoothing polymer was applied on top of the CFRP to create an optical surface. Then, a thin film of reflective silver was deposited, followed by a thin film of silicon dioxide as a protective layer. Finally, strips of solar cells were attached to the back of the concentrators (Figure 5). 
Table 3. Material properties and components modeled in sequentially coupled thermal-mechanical FEA.

\begin{tabular}{|c|c|c|c|c|c|c|c|}
\hline Material & $\begin{array}{l}\text { Conductivity } \\
(W / m K)\end{array}$ & $\begin{array}{l}\text { Specific } \\
\text { heat } \\
(m J / \text { tonne })\end{array}$ & $\begin{array}{l}\text { Density } \\
\text { (tonne } / \mathrm{mm}^{3}\end{array}$ & $\begin{array}{l}\text { Modulus } \\
(M P a)\end{array}$ & $\begin{array}{l}\text { Poisson's } \\
\text { ratio }\end{array}$ & $\begin{array}{l}\mathrm{CTE} \\
(p p m)\end{array}$ & $\begin{array}{l}\text { Components } \\
\text { modeled }\end{array}$ \\
\hline Polyimide & 0.12 & $1.09 \times 10^{9}$ & $1.42 \times 10^{-9}$ & 2,500 & 0.34 & 20 & flex PCB \\
\hline Copper & 398 & $3.85 \times 10^{8}$ & $8.93 \times 10^{-9}$ & 110,000 & 0.34 & 16.4 & flex PCB \\
\hline PMMA & 0.19 & $1.46 \times 10^{9}$ & $1.19 \times 10^{-9}$ & 3,220 & 0.40 & 80 & flex PCB \\
\hline PDMS & 0.15 & $1.5 \times 10^{9}$ & $9.5 \times 10^{-10}$ & 0.5 & 0.45 & 310 & $\begin{array}{l}\text { PV cell } \\
\text { strip }\end{array}$ \\
\hline Silicon & 124 & $7.13 \times 10^{8}$ & $2.33 \times 10^{-9}$ & 112,400 & 0.28 & 2.49 & $\begin{array}{ll}\text { PV } & \text { cell } \\
\text { strip } & \text { and } \\
\text { IC } & \end{array}$ \\
\hline $\begin{array}{l}\text { CFRP } \\
\text { (layup) }^{1}\end{array}$ & $\begin{array}{l}\text { Axial: } \\
9.75 \\
\text { Transverse: } \\
9.75 \\
\text { Out-of- } \\
\text { plane: } \\
1.5\end{array}$ & $7.53 \times 10^{8}$ & - & - & - & - & $\begin{array}{l}\text { concentrators, } \\
\text { frames, s- } \\
\text { springs }\end{array}$ \\
\hline $\begin{array}{l}\text { CFRP } \\
(\text { ply })^{2}\end{array}$ & - & - & - & $\begin{array}{l}\text { E1: } \\
\text { 128,000 } \\
\text { E2: } 6,500 \\
\text { G12: } \\
7,500 \\
\text { G13: } \\
7,500\end{array}$ & $\begin{array}{l}\text { Nu12: } \\
0.35\end{array}$ & 0.56 & $\begin{array}{l}\text { concentrators, } \\
\text { frames, s- } \\
\text { springs }\end{array}$ \\
\hline
\end{tabular}

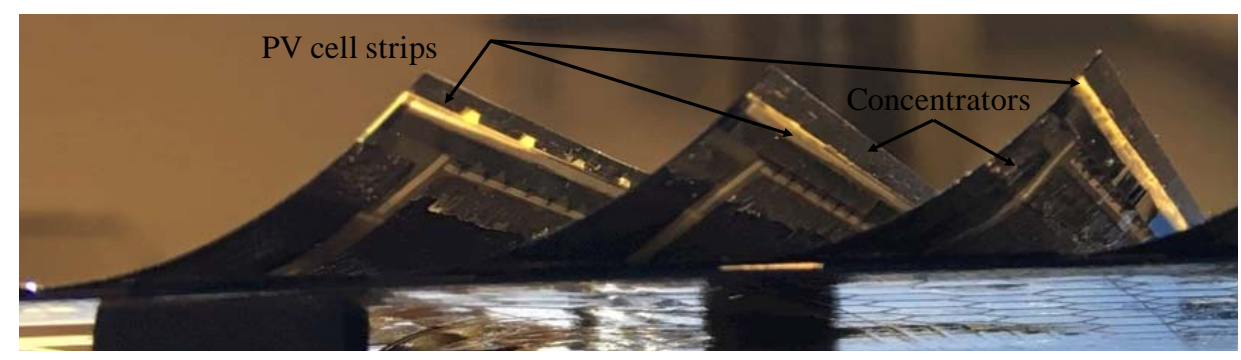

Figure 5. Solar cell strips attached to the back of concentrators.

Concentrators are designed to focus incident light over a $1 \mathrm{~mm}$ wide solar cell strip at a nominal distance of approximately $15 \mathrm{~mm}$. Since deviations from the design shape could significantly degrade performance, solar concentrator manufacture was critical in prototype development.

To quantify the difference between manufactured concentrator shapes and the desired shape we generated $3 \mathrm{D}$ representations of the concentrators using digital image correlation and a laser scanner instrument (FaroArm) and computed the following parameters:

1. average, range, and standard deviation of the best fit quadratic coefficient along the concentrator length;

2. shape efficiency, i.e., the percentage of light focused on an ideally positioned theoretical solar cell in front of the concentrator;

3. ideal location of theoretical solar cell capturing the maximum percentage of light. 
The quadratic coefficient (designed to be 0.033 ) variance along the concentrator length provides a measure of shape consistency along the length of the concentrator. The global average value of the quadratic coefficient is not sufficient as it may change along the concentrator. The maximum percentage of light (ideally 100\%) focused on an theoretically positioned solar cell was computed by ray tracing and is a global measure of concentrator quality. The location of a theoretical solar cell (ideally corresponding to the cell location as shown in Figure 3) indicates whether a solar cell can realistically be positioned to capture light from the concentrator, given overall design constraints.

Steel molds with different parabolic profiles were used to investigate the relationship between the mold profile and the resulting concentrator shape. Figure 6 a shows the average sample parabolic coefficient as a function of mold profile coefficient. Manufacturing process variability led to the possibility of using different parabolic coefficient molds for the actual prototype, as long as the shape deviation was acceptable. The acceptability criteria were that at least $80 \%$ of the light should be captured by a solar cell and that the pitch and backset should range between 14-16 $\mathrm{mm}$ and 0-3 $\mathrm{mm}$ respectively, to ensure assembly.

Of the manufactured concentrators, 25 out of $29(86 \%)$ met the acceptability criteria and 11 of those were used in the actual prototype. Figure 6(b)-(d) shows the distribution of the manufactured concentrators grouped by different performance criteria, for three molds: (b) efficiency, (c) ideal pitch, and (d) ideal backset. All concentrators with greater than $80 \%$ shape efficiency exhibited acceptable pitch and backset. Most concentrators (17 out of 25) exhibited ideal pitch slightly smaller than the design pitch of $15 \mathrm{~mm}$. Similarly most concentrators (13 out of 25) exhibited a backset greater than the design value of $2 \mathrm{~mm}$. Preliminary analysis attributes this to the shape of the concentrators systematically exhibiting greater parabolic coefficient than the design value of 0.033 , though still within an acceptable range. 


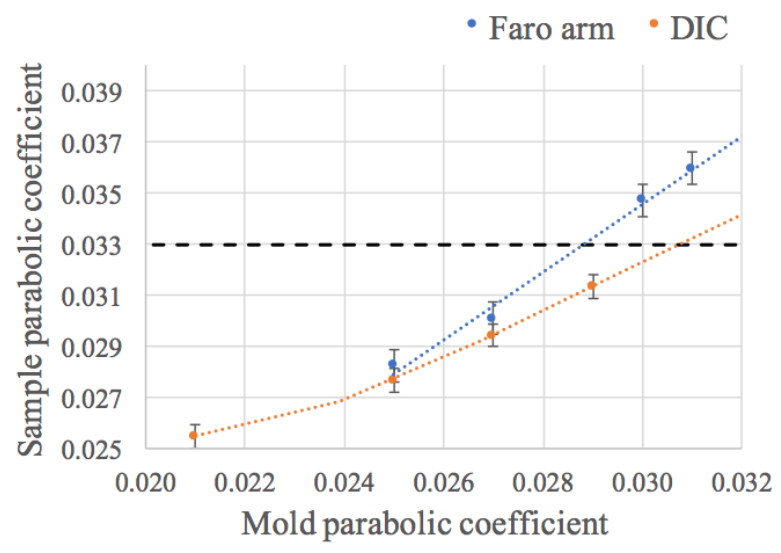

(a) Relationship between concentrators sample parabolic coefficient and mold parabolic coefficient

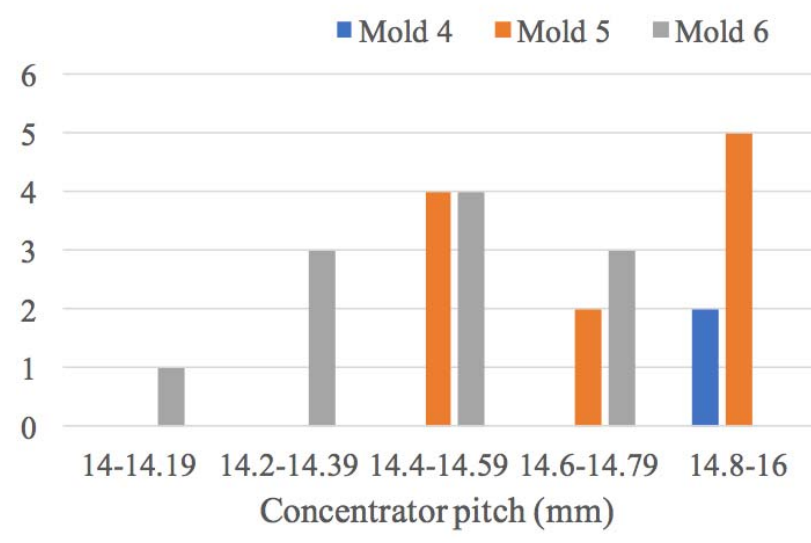

(c) Number of $>80 \%$ shape accuracy concentrators grouped by optimal pitch

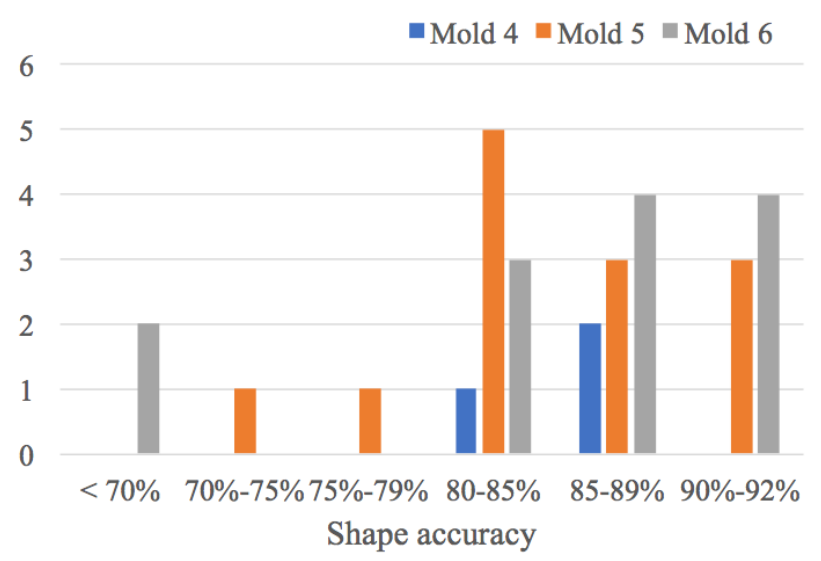

(b) Number of manufactured prototype concentrators grouped by shape accuracy

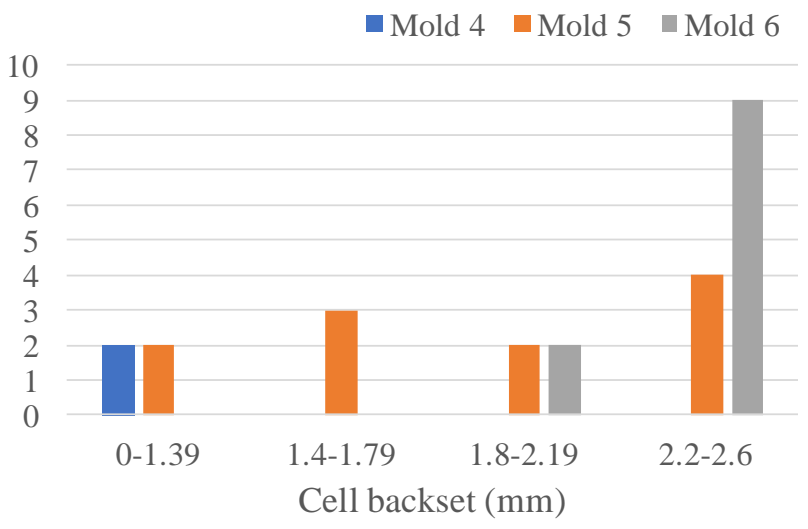

(d) Number of $>80 \%$ shape accuracy concentrators grouped by optimal backset

Figure 6. Distribution of concentrators manufactured for prototype by (a) shape accuracy; (b) optimal pitch; (c) and optimal backset

\section{III.B. Tile integration and assembly}

The prototype assembly procedure was designed to be robust and responsive to unexpected and unknown deviations in concentrator and overall tile shape (despite thorough concentrator shape measurement and analysis) and to also ensure that errors generated during each step of the assembly do not accumulate. An assembly structure (Figure 7) was designed with these objectives in mind. The assembly structure used pins to locate concentrators on sliders along a rail. Shims were placed between the sliders so that the concentrator pitch could be accurately controlled. Using this assembly structure, we developed an iterative assembly procedure comprising of nine steps:

1. select lot of 11 best concentrators based on measurements and analysis;

2. place best concentrator on back of assembly structure;

3. place next best concentrator on assembly structure, based on computational prediction and experimental observation;

4. attach PV cell strip to second concentrator under microscope;

5. verify power output of cell and optimize pitch by moving second concentrator and repeat steps 2-5 for all concentrators; 
6. bond concentrators to PV flex PCB with CFRP frame;

7. release completed PV plane from assembly structure;

8. attach s-springs to structurally separate the RF antenna plane from the RF power transfer plane;

9. assemble RF planes and PV planes with CFRP spacers.

Measurement of power output during step 5 was performed under the same solar simulator that the assembled tile would be tested, by measuring the current output of the solar cell strip under operational voltage. This measurement provided the redundancy of dynamically changing the pitch by moving the assembly structure's sliders and verifying that the most recently placed concentrator was receiving an acceptable level of power. If the power was unexpectedly low, that concentrator could be replaced with no impact to the already acceptable concentrator assembly behind. Figure 8 shows an example of data generated during step 5, for a particular pair of concentrators. The light incidence angle was also varied during the test to gain insight into the behavior of the concentrators, though the tile was designed for normal incidence. Data such as shown in Figure 8 was generated for all concentrator pairs and the final pitch for each pair was fixed for maximum current at normal incidence. Figure 9 shows top (a) and bottom (b) views of the tile prototype after completed assembly.

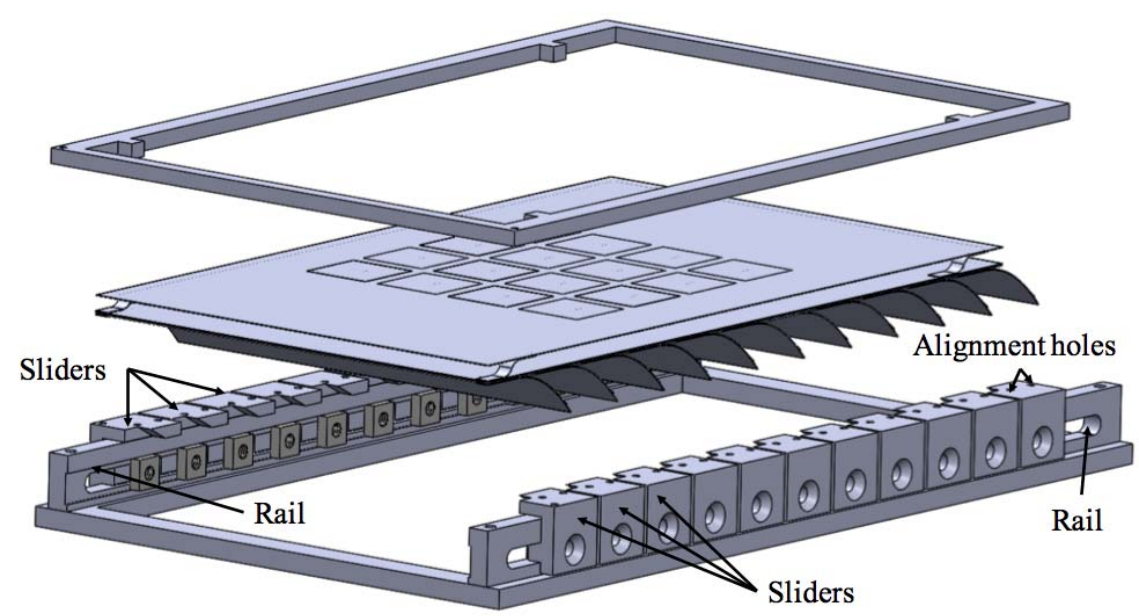

Figure 7. CAD model of the assembly structure used to control the concentrator pitch during assembly of the tile PV plane.

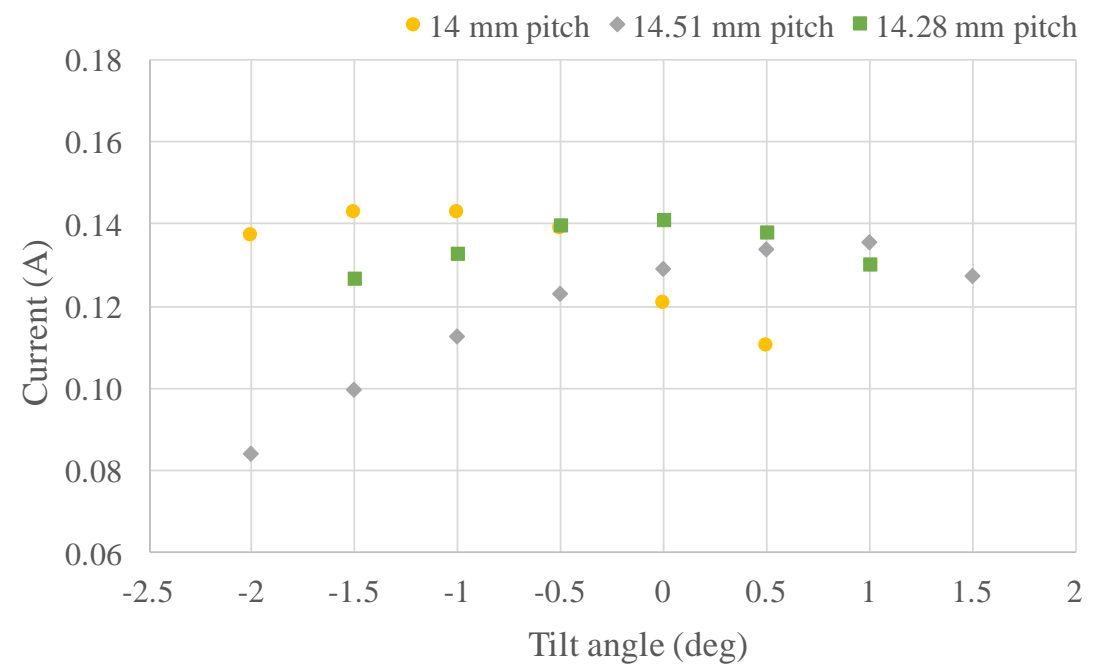

Figure 8. Current output of solar cell strip for particular concentrator pair measured during the tile assembly process under a solar simulator. The tilt angle and pitch were varied and the final concentrator pitch was chosen as the one that yielded the highest current output at normal incidence. 


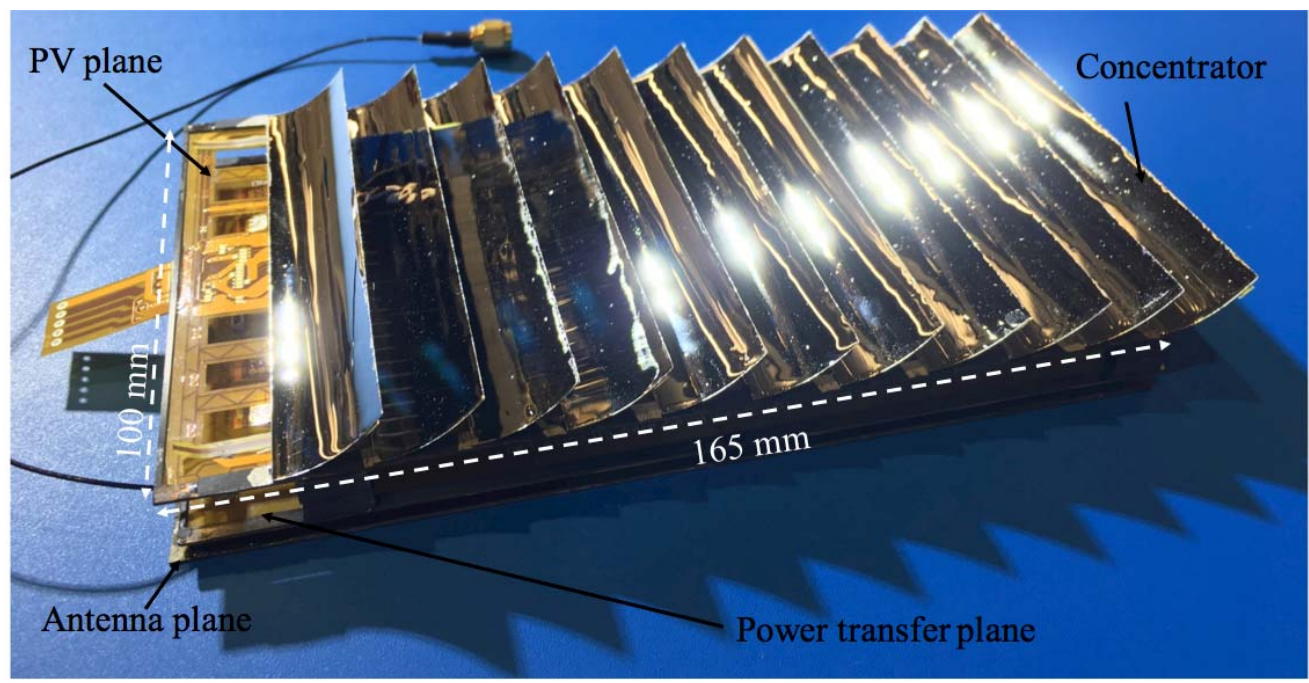

(a) top view

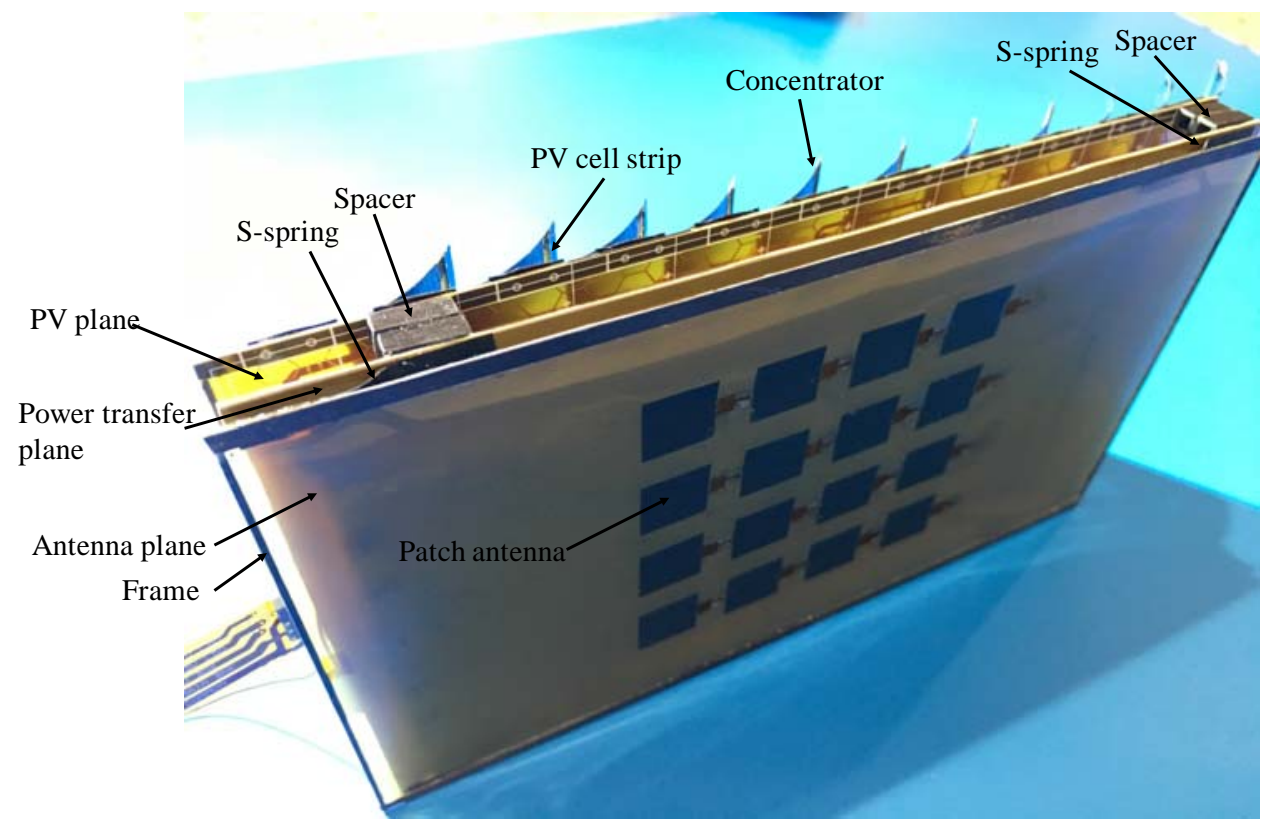

(b) bottom view

Figure 9. Top (a) and bottom (b) views of the first fully functional integrated tile prototype.

\section{Prototype performance and design iterations}

Functionality of the tile prototype shown in Figure 9 was demonstrated by placing the tile in a solar simulator emitting light at the solar spectral irradiance in space (AM0) at normally incident angle and wirelessly powering and lighting an LED located on a rectenna board at approximately $50 \mathrm{~cm}$ from the tile. Two key performance metrics are tile areal density $\left(\mathrm{g} / \mathrm{m}^{2}\right)$ and specific power collected and transmitted by the tile $(W / k g)$.

The tile prototype described here weighs $24.9 \mathrm{~g}$ and has an areal density of $1512 \mathrm{~g} / \mathrm{m}^{2}$. Table 4 shows a mass breakdown of the tile. A significant component of the tile mass is in flexible PCBs and concentrators. A concentrator, including the PV cell weighs $0.83 \mathrm{~g}$; concentrators account for $37 \%$ of the tile mass. In more detail, the CFRP part of the concentrator weighs $0.44 \mathrm{~g}$, the smoothing polymer and reflective layer weigh $0.15 \mathrm{~g}$ and the PV cell strip assembly weighs $0.24 \mathrm{~g}$. In the future, there is substantial opportunity to reduce the mass by incorporating thinner CFRP and smoothing layers. Additional sources of future mass reduction include integration of the PV flex and power transfer PCB's. The anticipated mass reduction for the next 
tile design iteration is shown in Figure 10.

Table 4. Tile prototype mass breakdown.

\begin{tabular}{ll} 
Component & Ma \\
\hline Solar concentrators & 9.1 \\
PV flex PCB and frame & 4.2 \\
Power transfer flex PCB, IC, heat sink, and frame & 8.3 \\
Antenna flex PCB and frame & 1.6 \\
S-springs & 0.2 \\
Spacers & 1.0
\end{tabular}

Total

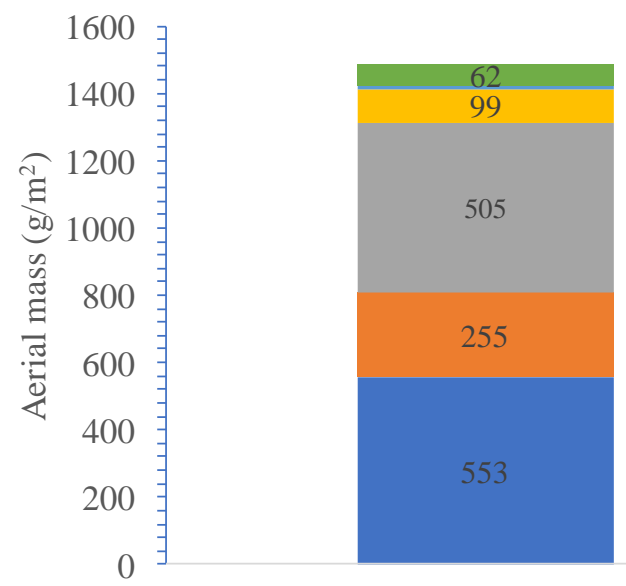

First prototype
Mass $(\mathrm{g})$

$9.1(11 \times 0.83)$

4.2

8.3

.6

1.0

24.9 (including $0.5 \mathrm{~g}$ adhesive)
- Spacers

- S-springs

Antenna flex PCB

RFIC and antenna ground plane flex PCB

- PV flex PCB

- Concentrator assembly

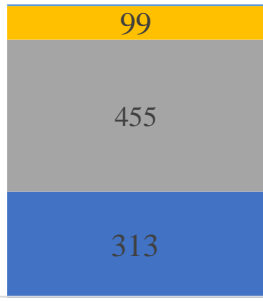

Next iteration

Figure 10. Areal density breakdown of the first manufactured integrated tile and projected next iteration.

The overall power collected by the tile is $3.1 \mathrm{~W}$, exceeding the $2.0 \mathrm{~W}$ requirement. This represents an efficiency of $14 \%^{\mathrm{a}}$ and $125 \mathrm{~W} / \mathrm{kg}$. The PV cell strip efficiency was $25 \%$, the overall optical efficiency was $74 \%$, the power collecting aperture being smaller than the physical aperture of the tile ${ }^{\mathrm{b}}$ resulted in $88 \%$ efficiency, and the PV cells not operating at their maximum power voltage resulted in $85 \%$ efficiency. Of the $3.1 \mathrm{~W}$ collected, $1.84 \mathrm{~W}$ were delivered to the IC for conversion to RF power. This loss is specific to the operating voltage of the IC and the PV cells and is expected to be mitigated in future integrated tile iterations. Finally, approximately $228 \mathrm{~mW}(9.2 \mathrm{~W} / \mathrm{kg})$ were transmitted at approximately $10 \mathrm{GHz}$ through 12 of the 16 patch antennas on the tile.

\section{Conclusion}

The first functional prototype of a lightweight $\left(1.5 \mathrm{~kg} / \mathrm{m}^{2}\right)$ integrated tile incorporating photovoltaic collection of solar power, conversion of this power to RF, and subsequent transmission of this power through a focused beam to power an LED has been demonstrated. Precise component manufacture, a robust assembly procedure, and finite element analysis of the tile's thermal-mechanical response, were critical elements of successful development.

Whereas functionality demonstration, and not performance, was the objective of this work, the performance characteristics of the tile are promising to make possible space solar missions in future tile iterations. With expected mass reduction and integration between the tile sub-assemblies, the overall specific power is

\footnotetext{
a Total incoming power over $165 \mathrm{~mm} \times 100 \mathrm{~mm}$ is $22.5 \mathrm{~W}$.

bThe front-most concentrator doesn't reflect onto a PV cell.
} 
expected to increase by one order of magnitude, which would indeed enable a swath of missions, assuming present day launch costs.

\section{Acknowledgments}

Financial support from the Northrop Grumman Corporation is gratefully acknowledged.

\section{References}

${ }^{1}$ Perlin, J., From space to earth: the story of solar electricity, Earthscan, 1999.

${ }^{2}$ Brown, W. C., "The history of power transmission by radio waves," IEEE Transactions on Microwave Theory and Techniques, Vol. 32, No. 9, 1984, pp. 1230-1242.

${ }^{3}$ Glaser, P. E., "Power from the sun: Its future," Science, Vol. 162, No. 3856, 1968, pp. 857-861.

${ }^{4}$ DOE/NASA, "Program Assessment Report Statement of Findings - Satellite Power systems Concept Development and Evaluation Program," Tech. rep., 1980.

${ }^{5}$ Carrington, C., Fikes, J., Gerry, M., Perkinson, D., Feingold, H., and Olds, J., "The Abacus/Reflector and integrated symmetrical concentrator-Concepts for space solar power collection and transmission," 35th Intersociety Energy Conversion Engineering Conference and Exhibit, 2000, p. 3067.

${ }^{6}$ Mankins, J. C., "A technical overview of the Suntower solar power satellite concept," Acta Astronautica, Vol. 50, No. 6, 2002, pp. 369-377.

${ }^{7}$ Oda, M., "Realization of the Solar Power Satellite Using the Formation Flying Solar Reflector," NASA Formation Flying symposium, Washington DC, Sept. 14-16, 2004, 2004.

${ }^{8}$ Seboldt, W., Klimke, M., Leipold, M., and Hanowski, N., "European sail tower SPS concept," Acta Astronautica, Vol. 48 , No. 5, 2001, pp. $785-792$.

${ }^{9}$ Sasaki, S., Tanaka, K., Higuchi, K., Okuizumi, N., Kawasaki, S., Shinohara, N., Senda, K., and Ishimura, K., "A new concept of solar power satellite: Tethered-SPS," Vol. 60, 02 2007, pp. 153-165.

${ }^{10}$ Rubenchik, A. M., Parker, J. M., Beach, R. J., and Yamamoto, R. M., Solar Power Beaming: From Space to Earth, Apr 2009.

${ }^{11}$ Mankins, J., "SPS-ALPHA: The First Practical Solar Power Satellite via Arbitrarily Large Phased Array," Tech. rep., Artemis Innovation Management Solutions LLC, 2012.

${ }^{12}$ Jaffe, P. and McSpadden, J., "Energy Conversion and Transmission Modules for Space Solar Power," Proceedings of the IEEE, Vol. 101, No. 6, June 2013, pp. 1424-1437.

${ }^{13}$ Arya, M., Lee, N., and Pellegrino, S., "Ultralight structures for space solar power satellites," 3rd AIAA Spacecraft Structures Conference, 2016, p. 1950.

${ }^{14}$ Kelzenberg, M. D., Espinet-Gonzalez, P., Vaidya, N., Roy, T. A., Warmann, E. C., Naqavi, A., Loke, S. P., Huang, J.-S., Vinogradova, T. G., Messer, A. J., Leclerc, C., Gdoutos, E. E., Royer, F., Hajimiri, A., Pellegrino, S., and Atwater, H. A., "Design and Prototyping Efforts for the Space Solar Power Initiative," IEEE PVSC, 2017. 